The development of the $N$ ational Blueprint: Increasing Physical Activity

A mong A dults A ge 50 and 0 Ider was sponsored by:

\title{
AARP
}

American College of Sports M edicine

A merican G eriatrics Society

The Centers for Disease Control and Prevention

The $\mathrm{N}$ ational Institute on A ging

The Robert Wood J ohnson Foundation

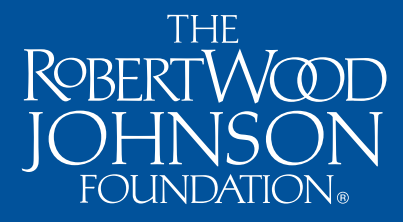

Route 1 and College Road East

Post O ff ice Box 2316

Princeton, N ew J ersey 08543-2316 


\section{National Blueprint}

\section{Increasing Physical Activity A mong A dults
A ge 50 and O Ider Activity A mong A dults
A ge 50 and 0 Ider}

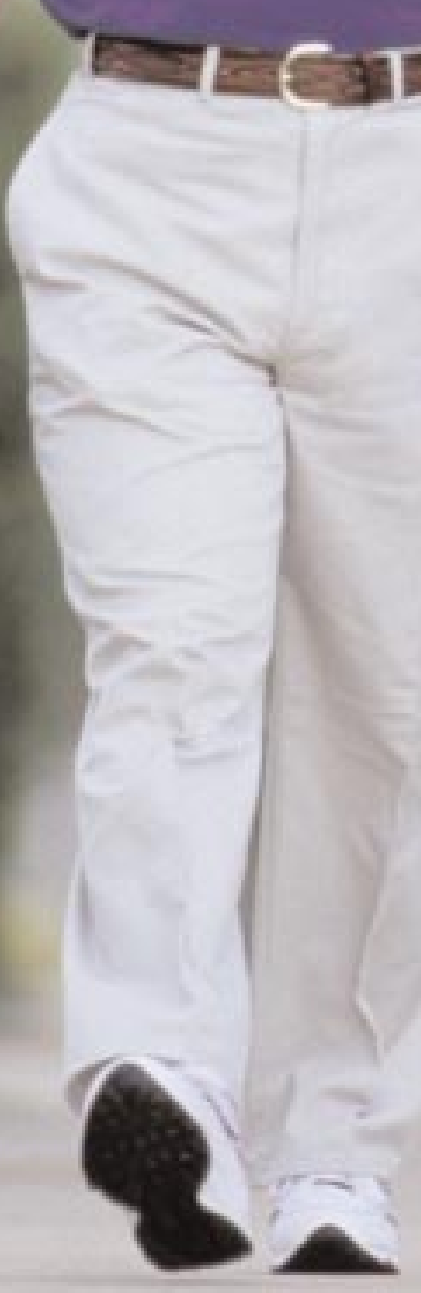




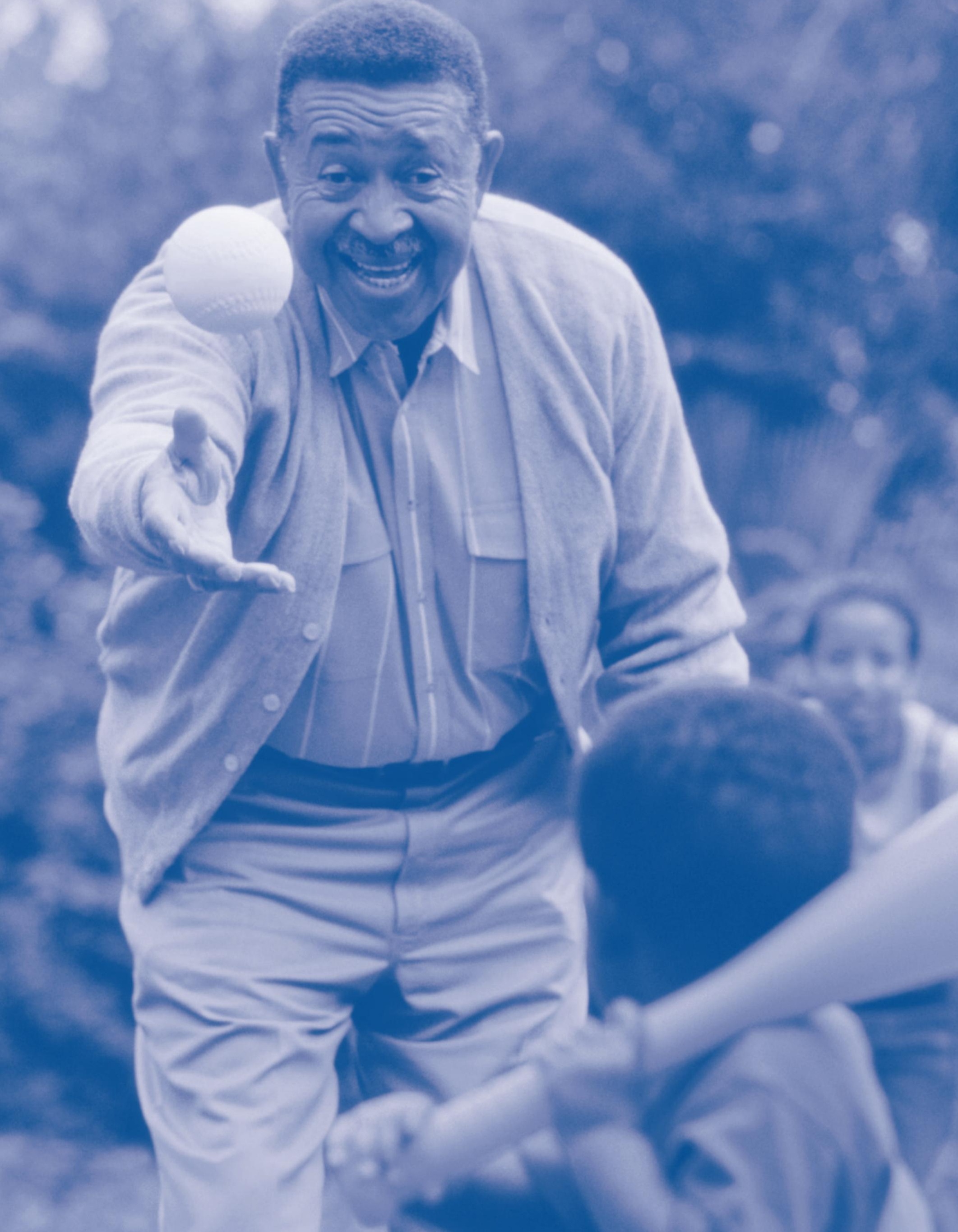




\section{Table of Contents}

Executive summary

SECTION ONE

Background

Vision and guiding principles 9

$\begin{array}{ll}\text { A snapshot of America's aging population } & 10\end{array}$

$\begin{array}{ll}\text { Types and benefits of physical activity } & 11\end{array}$

$\begin{array}{ll}\text { Demographic Shifts } & 12\end{array}$

$\begin{array}{ll}\text { Chronic Illness and the A ging Population } & 12\end{array}$

The benefits are significant: It's time to address physical activity

in the aging population

H ealthy People 2010 physical activity objectives

SECTION TWO

Developing solutions to increase physical activity

Complex barriers impede efforts to increase and maintain physical activity among older adults

Addressing the barriers and setting a strategic direction

\section{SECTION THREE}

M oving toward and beyond 2010: Turning strategies into action

The $\mathrm{N}$ ational Blueprint on Physical Activity A mong Adults A ge 50 and O Ider grew out of the need for a framework for planning, collaborative action, and social change among organizations and agencies involved in physical activity and/or aging. Six partner organizations led the effort to create this document (AARP, A merican College of Sports M edicine, A merican Geriatrics Society, The Centers for Disease Control and Prevention, $\mathrm{N}$ ational Institute on Aging, and The Robert Wood J ohnson Foundation). In addition, a conference was held in 0 ctober 2000 of approximately 50 interested organizations to provide input and recommendations. 


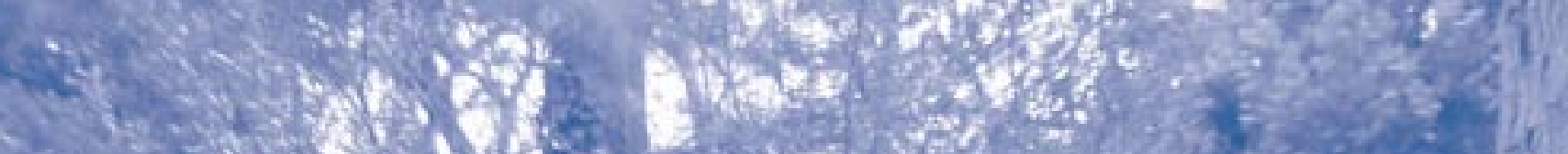

$d ?$

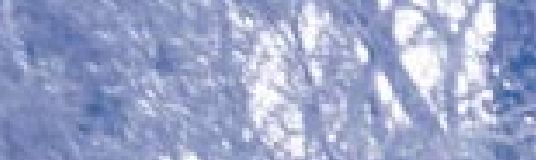

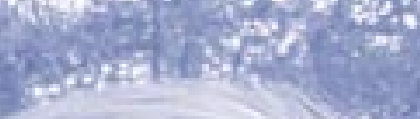

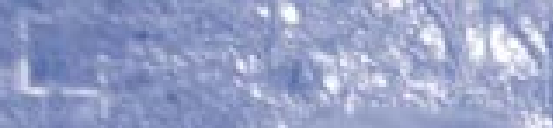

$(-3020$

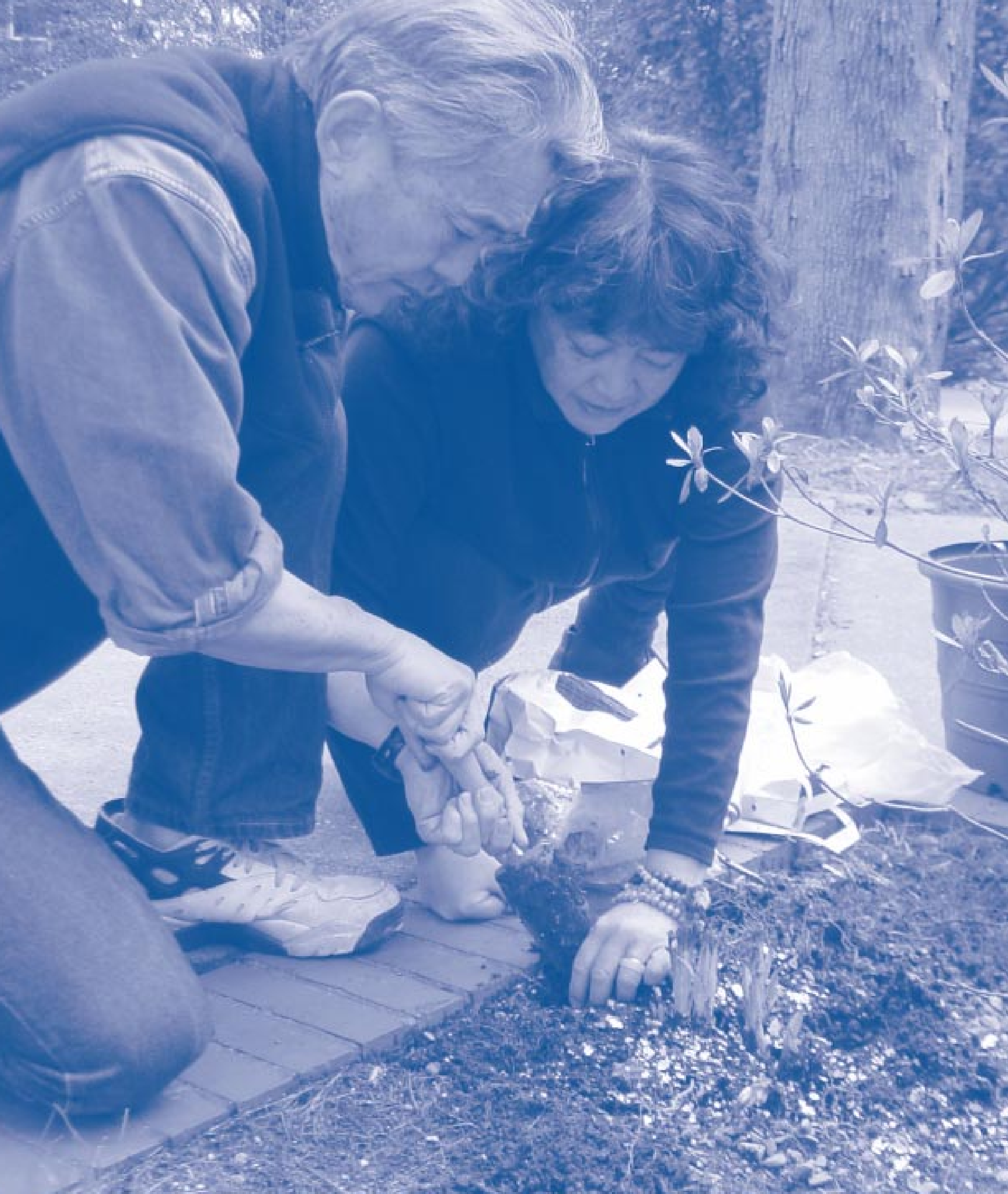




\section{Executive summary}

We developed the $\mathrm{N}$ ational Blueprint: Increasing Physical A ctivity A mong Adults A ge 50 and $O$ Ider as a guide for organizations, associations, and agencies to plan strategies to help people age 50 and older increase their physical activity. This plan synthesizes input from more than 65 individuals, representing 48 organizations with expertise in health, medicine, social and behavioral sciences, epidemiology, gerontology/geriatrics, clinical science, public policy, marketing, medical systems, community organization, and environmental issues.

Regular physical activity can bring dramatic health benefits to people of all ages and abilities, according to a substantial body of scientific evidence. M edia and health professionals often tout the benefits of exercise for younger and middle-aged people. But scientific evidence increasingly indicates that physical activity can extend years of active independent life, reduce disability, and improve the quality of life for older persons as well. Although the evidence is clear, it is not yet been translated into national action. That is the aim of this Blueprint.

The vision of the people who developed this document states:

We envision a society in which all people age 50 and older enjoy health and quality of life, which is enhanced through regular physical activity. We will inspire an approach to aging that encourages physical activity in all aspects of people's lives.

This document outlines steps to achieve this vision. The first section provides background on physical activity and health of Americans age 50 and older. The second section addresses the barriers to increasing physical activity among the aging population. It outlines suggested strategies related to research, home and community, workplace, medical systems, public policy and advocacy, and cross-cutting issues to overcome these barriers.

O rganizations are al ready working together to encourage physical activity among older A mericans. These groups include health care organizations, health providers, aging service organizations, the private sector, government, nonprofit, and philanthropic organizations. These efforts aim to help people maintain their health, reduce chronic illness and disability and enhance their well-being and functional abilities as they age.

The $\mathrm{N}$ ational Institute of A ging has laid excellent groundwork to support a national initiative to increase physical activity among mid-life and older adults. In addition this document aligns with the United States D epartment of $\mathrm{H}$ ealth and $\mathrm{H}$ uman Services H ealthy People 2010 objectives.

H owever, no national organization or coalition is systemically addressing physical activity and older Americans. No organization is taking into account the comprehensive health issues, medical systems and reimbursement, marketing, environmental issues, education, 
and research that are involved in helping older A mericans become physically active. $\mathrm{N}$ ot enough visible, physically active older role models exist at the community and national level. This document is intended to encourage more aggressive action, facilitate collaboration, and enhance development of additional ideas.

To translate this plan into action organizations will have to reach beyond their comfort zone. For example, many mid-life and older people are not likely to walk if they live in neighborhoods that have no sidewalks, or are dangerous.

Public health professionals will have to learn about local transportation planning and how to work with elected officials to encourage exercise friendly neighborhoods. Effective efforts to increase physical activity among older adults will require an integrated and collaborative approach that will involve community health professionals, health associations and agencies, planners, health care providers, employers, community centers, senior living facilities, transportation experts, community planners, and other diverse groups and organizations and areas of professional expertise.

This document outlines a variety of approaches to address barriers to physical activity among the age 50 and older population and suggests strategies to increase physical activity. The strategies are divided into five categories: research, home/community, workplace, medical systems, and public policy. In addition there is a category of "cross-cutting" strategies that relate to more than one of these areas. M arketing and communications strategies are integrated throughout the recommendations.

Research strategies identify steps needed in research, including medical, social, behavioral, policy, and marketing research. In many cases, integrating program development, implementation, and evaluation will be the most effective way to implement these strategies.

The home/community strategies take into account the nature of how people live and carry out the normal tasks of daily life.

Workplace strategies recognize that people generally work in or near the community in which they live, and work sites can often operate as a community resource or center.

M edical systems are broadly defined to include health care delivery centers, e.g. clinicians' offices, clinics, medical centers, hospitals, and health-care reimbursement organizations. Professional education and continuing education are covered in these strategies.

Public policy and advocacy strategies can be carried out at the local, state, and national level. Effective policy/advocacy initiatives should include coordination and collaboration among organizations and associations that share priorities and objectives. 
The effective implementation of the strategies outlined in this Blueprint hinges on a number of factors:

- organizations will need to identify clearly which strategies they wish to address, and collaborate with other groups that share an interest in that (those) strategy(ies.);

- organizations should develop formal coalitions and partnerships with other like-minded organizations; and

- organizations should establish systems to facilitate communication and exchange information on best practices.

This Blueprint is designed to support an increase in physical activity among aging adults, and to improve the health and well-being of all Americans. The key to success lies in developing and channeling resources, and working collaboratively to move the evidence about the benefits of physical activity into national action. 


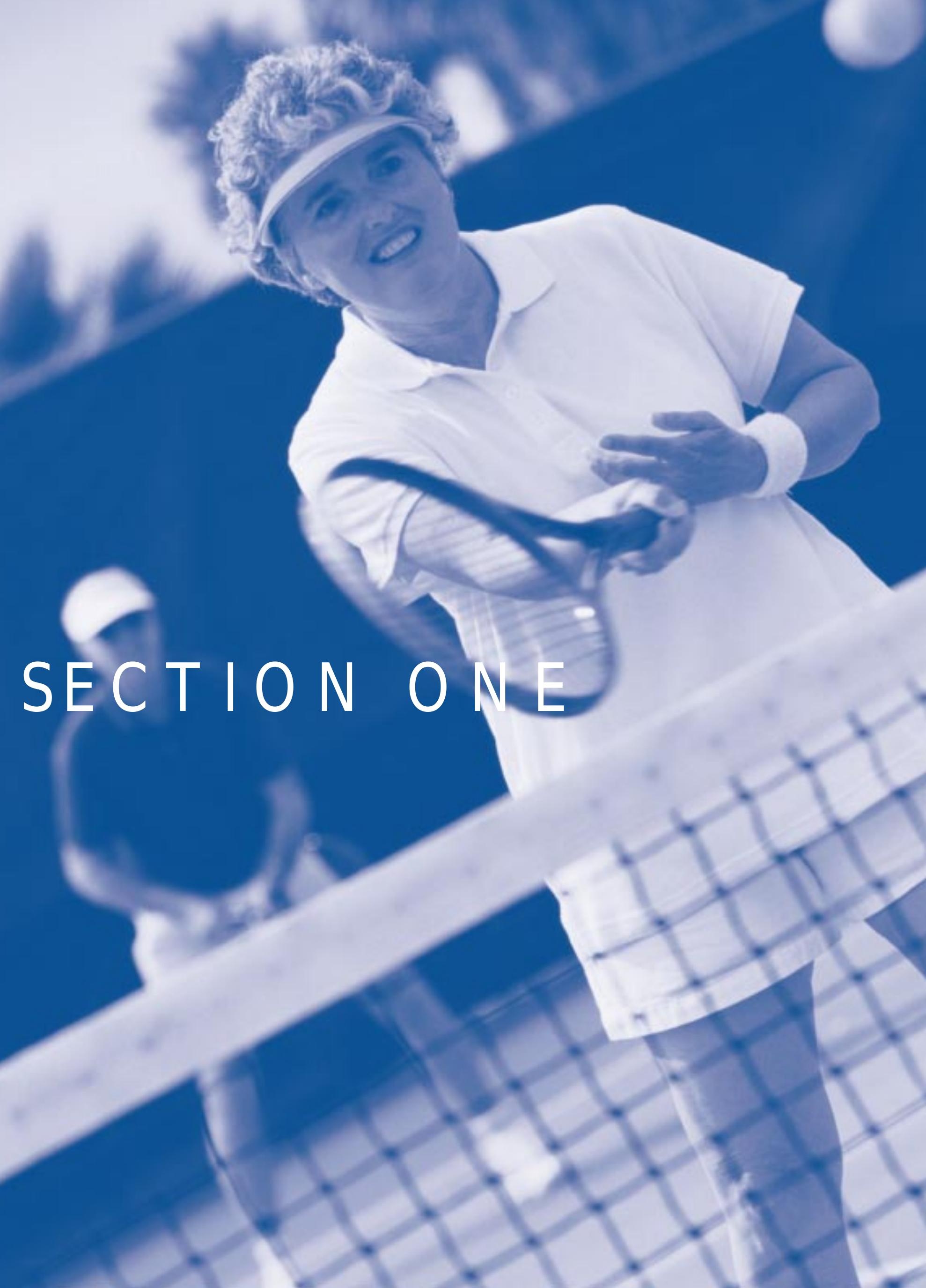




\section{Background}

On A pril 4 and 5, 2000, The Robert Wood J ohnson Foundation ${ }^{\circledR}$ (RW JF) hosted a "Technical Experts Working Group M eeting on Physical A ctivity and M id-life and O Ider Adults" in N ashville, Tennessee. The 23 participants (representing science and medicine, public health, aging services, communications, academia, government, and RWJ F) reviewed the current situation related to increasing physical activity among mid-life and older adults, discussed some of the most important gaps and opportunities for program development, and considered elements of effective interventions.

Discussion at the A pril 2000 technical experts meeting highlighted the fact that the issue of physical activity and the 50 and older population is currently under-addressed, is complex, is a difficult issue to undertake, and lacks adequate leadership. In addition, it is an issue that is poorly understood and widely unrecognized. Those organizations that have been working in the area of physical activity and the 50 and older population are often working in isolation. Efforts to address the issue have been diffuse, lacking adequate resources and communications channels.

Participants recommended that a national "blueprint" be developed to help guide and focus the work of the organizations that are involved, or interested in, physical activity among people age 50 and older, as well as to engage the participation of additional groups.

As an outcome of the $\mathrm{N}$ ashville meeting representatives of the AARP, the A merican College of Sports M edicine, A merican Geriatrics Society, The Centers for Disease Control and Prevention, N ational Institute on A ging, and The Robert Wood J ohnson Foundation formed a Steering Committee and developed an agenda for a Blueprint Conference, which was held 0 ctober 30-31, 2000. The conference provided a forum for the participating organizations to discuss and strategize ways to increase physical activity among the age 50 and older population. This document is the outcome report of that conference, and represents the work of the Steering Committee as well as the conference participants and expert reviewers.

\section{Vision and guiding principles}

The individuals and organizations that hel ped develop this document crafted the following vision statement:

We envision a society in which all people age 50 and older enjoy health and quality of life, which is enhanced through regular physical activity. We will inspire an approach to aging that encourages physical activity in all aspects of people's lives. 
In support of this vision, the contributors to the Blueprint outlined these guiding principles:

- We share a long-term commitment to collaborate to support, endorse, and enhance regular physical activity for all people age 50 and older.

- We will work through community programs, policy, research, and communications activities that assure that resources and opportunities for physical activity are promoted, supported, and sustained in the community, workplace, home, and health care setting.

- We recognize the increasingly diverse sociological, economic, and demographic changes in the aging society (and society in general). We will also take into account the changing roles of technology in our society and changes in health care delivery and reimbursement systems.

- We will address the broad range of people from various ethnic, cultural and economic backgrounds, of all races, and both genders, from active and vigorous individuals, to people with disabilities, to the frail elderly.

- Wewill encourage mid-life and older adults to participate in leadership and decision-making.

- O ur efforts will consider mid-life and older adults' preferences for physical activity, such as settings and types of activity.

- We will base and evaluate initiatives and programs on available scientific evidence.

\section{A snapshot of America's aging population}

Increases in the number and proportion of our population over age 65 , and the dynamic changes within the aging population itself, represent perhaps the most dramatic change in A merican society in this century. And projections call for additional dramatic "graying" of America well into the twenty-first century. At the turn of the twentieth century, approximately four percent of the United States population was over age 65. Life expectancy at age 65 for the average A merican is now 17 years, a full five years longer than at the turn of the century. ${ }^{1}$

John W. Rowe, M D and Robert L. Kahn, PhD

Successful Aging

D emographic data tells us that the number and proportion of older people in the US population will continue to grow at a very rapid pace. A ging in the 21st century will be characterized by a steep rise in the population age 85 and older and increased racial and ethnic diversity. ${ }^{2}$ In the year 2000, an estimated 35 million people, 13 percent of the population, were age 65 or older. ${ }^{3}$ By 2030, 20 percent of A mericans, about 70 million people, will have passed their 65 th birthday. ${ }^{4}$ T he population aged 85 and above is the fastest growing segment of the older population. ${ }^{5}$ 
The aging of our country will touch on all aspects of life. Employers will be faced with both early retirements of workers and veteran workers who choose to remain in the work force throughout their $60 \mathrm{~s}, 70 \mathrm{~s}$ and into their later years. Some older workers will leave retirement to reenter the work force. Community services will change to adapt to the needs of older people with more senior centers, more accessible public transportation and expanded programs to meet the diverse needs and interests of a growing heterogeneous population.

Economic gaps in the older population have implications for where seniors live, their opportunities to remain or become physically active, and the health care they receive. The age 50 and older population has differing interests and demands for lifestyle options, continuing education, medical services, and recreation and leisure activities.

\section{Types and benefits of physical activity}

O rganizations that include The $\mathrm{C}$ enters for Disease $\mathrm{C}$ ontrol and Prevention, the $\mathrm{N}$ ational Institute on A ging, American College of Sports M edicine, and the A merican $\mathrm{H}$ eart Association agree that individuals should be encouraged and assisted in developing and maintaining a practice of regular physical activity throughout their lives. Physical activity is regular if activities are performed most days of the week, preferably daily ${ }^{6}$.

The following elements are aspects of physical activity: cardio respiratory (aerobic) endurance, muscle strength and endurance, balance, and stretching.

Cardio respiratory (aerobic) endurance activities increase heart rate and breathing for extended periods of time. They improve the health of the heart, lungs and circulatory system, and have been shown to help prevent or delay some diseases. Endurance exercises are activities that increase the heart rate and require a persistent supply of oxygen to promote sustained activity, e.g. walking, jogging, swimming, bicycling. The goal for cardiovascular endurance exercise is to build up to at least 30 minutes of endurance exercise on most or all days. ${ }^{7}$

M uscle strength and endurance (resistance) exercises make older adults strong enough to do the things that they need to do and the things they like to do. Strength and endurance exercises for all major muscles should be done at least twice a week. ${ }^{8}$

Balance exercises help prevent falls, a major cause of disability for older adults. Balance exercises can be incorporated into strength training exercises. Any of the lower-body exercises for strength that require standing are also balance exercises. ${ }^{9}$

Stretching helps keep the body limber and flexible and can help prevent injuries. Stretching gives more freedom of movement. Stretching should be done regularly before and after exercise. ${ }^{10}$ 


\section{Demographic shifts}

The following statistics illustrate some aspects of the enormous demographic shift.

- In the year 2000 an estimated 35 million people, 13 percent of the population, were age 65 and older. ${ }^{11}$

- By 2030, 20 percent of Americans, about 70 million people, will have passed their 65th birthday. ${ }^{12}$

- The "Baby Boom" generation will begin to turn 65 in 2009 and the number of people age 65 and older is expected to triple to 93 million within the next 50 years. ${ }^{13}$ The youngest of the "Baby Boomer" generation will reach age 65 in 2030. ${ }^{14}$

- The population aged 85 and above is the fastest growing segment of the older population. ${ }^{15}$

- By 2050 the size of the 85 plus age group will increase to almost 5 percent of our population. ${ }^{16}$

- There were about 65,000 people aged 100 or older in 2000 . The number of centenarians is projected to grow quickly so that there may be as many as 381,000 by $2030 .{ }^{17}$

\section{Chronic illness and an aging population}

W hile some A mericans remain in reasonably good health as they advance in years, the following statistics illustrate sobering concerns that illustrate how many A mericans are aging.

- 88 percent of those over 65 have at least one chronic health condition ${ }^{18}$ and 21 percent of people 65 and older have chronic disabilities. ${ }^{19}$

- 35 percent to 50 percent of women age 70 to 80 have difficulty with general mobility tasks like walking a few blocks, climbing a flight of stairs, or doing housework. ${ }^{20}$

- 24 percent of people over 50 who have hip fractures die within a year. ${ }^{21}$

In many cases, physical activity can have a positive impact reducing or helping to manage many of these health conditions. 


\section{The benefits are significant: It's time to address physical activity in the aging population}

With the remarkable increases in longevity, and increasing awareness that risks associated with advancing age may be reversible, health promotion, not just disease prevention, is emerging as an important theme in geriatrics. The goal of these efforts in old age need not always be prevention - sometimes delay is really all we need. The benefits of delaying the onset of disease are very substantial, and problems in old age such as heart disease and cancer are often subject to delay, if not to prevention. Since many individuals in their eighth and ninth decades of life have many life-threatening conditions at once, delay in the emergence of a single disease, such as cancer, for as much as five years will dramatically reduce disability, suffering, and the cost of medical care. This reduction in the total period of disability - formally known as "compression of morbidity" - is the main goal of prevention initiatives in late life.

The nice thing is, however, that some of the same lifestyle changes that reduce the risk of one disease may delay or cut the risk of others as well..$^{22}$

John W. Rowe, M D and Robert L. Kahn, PhD

Successful Aging

A strong body of scientific evidence exists that shows physical activity can contribute to improved health and functional ability, as well as reduce chronic illness and disability. Consider the following facts:

- $M$ iddle age and older men and women who engage in regular physical activity have significantly higher high-density lipoprotein (HDL) cholesterol levels than do those who are sedentary. ${ }^{23} \mathrm{H} \mathrm{DL}$ cholesterol, sometimes called the "good cholesterol" helps reduce risk of cardiovascular disease.

- Strength training helps people maintain and improve their balance and may help reduce falls and fractures. Balance training helps reduce falls as well. ${ }^{24}$

- Regular physical activity reduces the risk of dying prematurely, developing diabetes, developing high blood pressure, and developing colon cancer. It reduces feelings of depression and anxiety, helps control weight, helps maintain healthy bones and muscles, and promotes psychological well-being. ${ }^{25}$

- Several studies suggest that exercise training improves cardiovascular fitness, enhances muscular strength, increases joint mobility and improves functional capacity of people with arthritis. ${ }^{26}$

While scientific evidence makes it clear that regular physical activity improves well-being, and contributes to the prevention or delay of disease (see Table 1, page 16), the physical activity profile of A merica's aging population looks dour. 
- A pproximately 34 percent of the population age 50 and older is sedentary. ${ }^{27}$

- 33 percent of men and $50 \%$ of women age 75 and older engage in no leisure-time physical activity. ${ }^{28}$

- The prevalence of inactivity among white women age 75 and older is 47.4 percent, $59.2 \%$ among black men age 75 and older, and an alarming 61 percent among black women age 75 and older..$^{29} \mathrm{Compared}$ to the 37 percent rate of inactivity among white men age 75 and older, these data highlight disparities in inactivity among different gender and racial/ethnic groups.

- Fewer than 50 percent of older adults report ever having received a suggestion to exercise from their physicians. ${ }^{30}$

Clearly, we need to take greater initiative to communicate physical activity recommendations and to support increased regular physical activity among mid-life and older adults.

Because of their low functional status and high incidence of chronic disease, there is no segment of the population that can benefit more from exercise than the elderly.

American College of Sports M edicine Exercise Training Guidelines for the Elderly 


\section{Healthy People 2010 Physical Activity Objectives ${ }^{31}$}

Recognizing that physical activity plays a vital role in health promotion and disease prevention, The Centers for D isease Control and Prevention and the President's Council on Physical Fitness and Sports, and other health agencies and organizations outlined a number of objectives related to physical activity as part of the $\mathrm{H}$ ealthy People 2010 $\mathrm{O}$ bjectives for Improving $\mathrm{H}$ ealth. These include:

- reduce the proportion of adults who engage in no leisure-time physical activity from 40 percent to 20 percent;

- increase the proportion of adults who engage regularly, preferably daily, in moderate physical activity for at least 30 minutes per day from 15 percent to 30 percent;

- increase the proportion of adults who engage in vigorous physical activity that promotes the development and maintenance of cardio respiratory fitness three or more days per week for 20 minutes or more minutes per occasion from 23 percent to 30 percent;

- increase the proportion of adults who perform physical activities that enhance and maintain muscular strength and endurance from 18 percent to 30 percent;

- increase the proportion of adults who perform physical activities that enhance and maintain flexibility from 30 percent to 43 percent;

- increase the proportion of the nation's public and private schools that provide access to their physical activity spaces and facilities for all persons outside normal school hours;

- increase the proportion of work sites offering employer-sponsored physical activity and fitness programs from 46 percent to 75 percent;

- increase the proportion of trips made by walking from 17 percent to 25 percent;

- increase the proportion of trips made by bicycling from .6 percent to 2 percent; and

A lthough these objectives are not age-specific, they can serve as a general framework for goals for physical activity among the age 50 and older population. In some cases, age-specific recommendations are available for H ealthy People 2010 objectives. 
Table 1

The following chart illustrates the some of the health benefits that can be realized from regular physical activity.

\begin{tabular}{ll} 
HEA LTH ISSUE & BEN EFIT S O F PH Y SICA L AC T IV ITY \\
\hline Cardiovascular health & - Improves myocardial performance \\
- Increases peak diastolic filling \\
- Increases heart muscle contractility \\
- Reduces premature ventricular contractions \\
- Improves blood lipid profile \\
- Increases aerobic capacity \\
- Reduces systolic blood pressure \\
- Improves diastolic blood pressure \\
- Improves endurance
\end{tabular}

\begin{tabular}{|c|c|}
\hline O besity & $\begin{array}{l}\text { - Decreases abdominal adipose tissue } \\
\text { - Increases lean muscle mass } \\
\text { - Reduces percentage of body fat }\end{array}$ \\
\hline Lipoproteins/G lucose Intolerance & $\begin{array}{l}\text { - Reduces low-density lipoproteins } \\
\text { - Reduces cholesterol/very low density lipoprotein } \\
\text { - Reduces triglycerides } \\
\text { - Increases high-density lipoproteins } \\
\text { - Increases glucose tolerance }\end{array}$ \\
\hline Osteoporosis & $\begin{array}{l}\text { - Slows decline in bone mineral density } \\
\text { - Increases bone density }\end{array}$ \\
\hline Psychological well-being & $\begin{array}{l}\text { - Improves perceived well-being and happiness } \\
\text { - Increases levels of catechotamines, norepinephrine } \\
\text { and serotonin }\end{array}$ \\
\hline $\begin{array}{l}\text { M uscle weakness and } \\
\text { functional capacity }\end{array}$ & $\begin{array}{l}\text { - Reduces risk of musculoskeletal disability } \\
\text { - Improves strength and flexibility } \\
\text { - Reduces risk of falls due to increased strength } \\
\text { - Reduces risk of fractures } \\
\text { - Increases reaction time, quadriceps strength } \\
\text { - Sustains cerebral perfusion and cognition }\end{array}$ \\
\hline
\end{tabular}


"Increases in the number and proportion of our population over age 65, and the dynamic changes within the aging population itself, represent perhaps the most dramatic change in A merican society in this century. And projections call for additional dramatic "graying" of A merica well into the twenty-first century." 


\section{Developing solutions to increase physical activity}

Activity-friendly communities will be organized to provide age 50 and older adults with multiple opportunities for active aging. A major prerequisite for active aging is the maintenance of physical activity throughout the lifespan. In order to assist in the maintenance of physically active lifestyles, it is essential that policies and programs build on older people's preferences and interests and that a variety of physical activity options are made available.

Employers will offer activity-friendly environments to employees. They will do this because employees desire such an environment and ideally because there is community support for work site related physical activity initiatives.

$\mathrm{H}$ ealth care systems will provide access to physical activity information, resources, and counseling to their older consumers. These systems will use evidence-based protocols to link assessments to intervention, will evaluate the effectiveness of systems promoting physical activity, and will serve as change agents and model employers regarding physical activity.

Goal statements by developers of Blueprint

Addressing the issue of physical activity and the aging audience is not a simple matter. The population age 50 and older is extremely diverse. When organizations develop, implement, and evaluate physical activity programs and initiatives for the mid-life and older population they will need to take into account age, gender, income, attitudes, race and ethnic background, geography, education, and marital status. For example, this age group encompasses everyone from people who run two or three marathons a year to very frail elderly who are confined to a wheelchair. It includes retired CEO s and retired janitors, people who live in congested cities and those who live on farms miles away from the nearest town.

When organizations attack the problem of sedentary lifestyles, they need to address the many factors that influence a person's daily life. $\mathrm{O}$ ften, this means that organizations need to engage multiple levels of social infrastructure.

Consider this example: A 70-year-old woman who is recently widowed has not been physically active beyond the routine housework she did for 50 years in taking care of her family. She is depressed over the loss of her husband and just one of her children lives nearby. She likes the idea of walking with friends but she lives in a subdivision with no sidewalks. She does not drive, and there is no public transportation service that will take her to either an area park or shopping mall during mid-day, where she might join her friends for walking. This woman understands the benefits of walking, and is motivated to engage in this activity. But transportation and community design factors create barriers that could result in no activity.

$H$ ealth and service organizations for the aging will need to recognize the integrated roles of community planning, design, architecture, and transportation and work closely with these groups. 
This Blueprint recognizes the importance of "delivery channels" for offering programs and solutions to increasing physical activity for older adults (see Table 2). Delivery channels represent places or systems where people engage in everyday behaviors. They include where people live; where people work; where they receive health care and medical treatment, and other social support networks. O rganizations that want to help age 50 and older people become more physically active need to consider the home and community situations of individuals in order to have a positive impact on enabling people to become more physically active.

O ngoing research, particularly in the areas of epidemiology and behavioral medicine, needs to be supported and expanded so that professionals can better understand how to develop programs that will help older adults remain physically active.

In addition, changes within the health care delivery system need to be evaluated to assure that older adults receive appropriate information, counseling, and resources related to physical activity. These changes include training for health care providers (for both clinicians and allied health professionals), reimbursing for this counseling, and developing clinical counseling guidelines.

O rganizations also need to explore new models and new avenues to develop, integrate, and implement physical activity initiatives. These might include working with transportation organizations and community planners to assure that in decision-making, communities look for solutions that will enable citizens to remain or become more physically active. People should be able to safely walk to stores, banks, and post offices and be able to safely go to parks, pedestrian malls, community and fitness centers, and to other community resources and services. 
Table 2

A dapted from J. B. M cK inlay's Population-Based H ealth Promotion M odel ${ }^{32}$. This model points out that the success of short-term, and maintenance of long-term, behavior change requires approaches combining downstream with midstream and upstream interventions.

Type of intervention (or delivery channel)

D O W N ST REA M

Description:

Individual-level interventions for those

Examples of Specific Activities:

who possess the risk factor (e.g. sedentary

- Group or individual counseling

lifestyle) or suffer from risk-related

diseases or conditions (e.g. obesity,

- Patient health-education and cognitive behavioral interventions

diabetes, etc.) with an emphasis on

- Self-help programs and tailored health changing, rather than preventing, communications health-damaging behaviors.

M IDST REAM

Description:

Population-level interventions that target defined populations for the purpose of changing or preventing health-damaging behaviors, and involve mediation through important organizational channels or natural environments.
Examples of Specific Activities

- Work site and community-based health promotions and disease prevention programs

- Primary care screening and intervention programs that reach entire populations

- Community-based interventions focused on defined at-risk populations (e.g. physical activity programs for older adults)

UPSTREAM

Description:

$\mathrm{M}$ acro-level state and national public policy and environmental interventions to strengthen social norms and supports for healthy behaviors and to redirect unhealthy societal and industry counter forces.
Examples of Specific Activities

- $\mathrm{N}$ ationwide public education and media campaigns

- Economic incentives (e.g. reimbursement for health behavior change treatments)

- Policies reducing access to unhealthy products (e.g. pricing, access, product design)

- Policies reducing the advertising and promotion of unhealthy products and behaviors 


\section{Complex barriers impede efforts to increase and maintain physical activity among older adults}

There are many barriers to increasing physical activity among adults age 50 and older. Despite a solid base of evidence supporting the positive impact of regular physical activity and the mid-life and older population, including work done by the $\mathrm{N}$ ational Institute on A ging, The Centers for Disease Control and Prevention, the A merican Geriatrics Society, and other leading health groups, not enough national and community-based organizations are able to focus adequate resources on physical activity and the age 50 and older population.

N o national organization or coalition is systemically addressing physical activity and older A mericans by taking into account comprehensive health issues, medical systems and reimbursement, marketing, environmental issues, education, and research. There are not enough visible physically active older role models at the community and national level.

Adding to this is the fact that societal norms have engineered physical activity out of many routine activities. For example, drive-through windows mean that people no longer need to even walk from their car to a fast-food restaurant or bank. The majority of people drive even short distances on routine errands, and seek parking spots that will allow them minimal walking. Household conveniences have in many ways enhanced our lives, but have also eliminated much physical activity.

Participants in the development of the Blueprint document identified some of the key barriers under the categories of research, home and community, workplace, medical systems, public policy, and marketing and communications. These categories are a framework to enable organizations to begin to identify areas where they might work to overcome or eliminate obstacles.

\section{RESEARCH}

- While a growing body of research documents the benefits of physical activity, there is little guidance on what types and amounts of physical activity are needed for specific health outcomes.

- Few studies have examined strategies for achieving long-term increases in physical activity.

- There has been inadequate translation of research findings into intervention strategies that are practical, and that can be widely incorporated into ongoing home and community settings. 
HOME AND COM MUN ITY

- $M$ any neighborhoods and communities are poorly designed or unsafe. They may be engineered in a manner that discourages regular physical activity among older adults. Some neighborhoods have no sidewalks, other areas are in the midst of busy thoroughfares, making it dangerous to cross the street to a nearby store.

- Few models exist for an integrated community approach to enable physical activity. Community resources (senior centers, senior residences, community centers, neighborhoods/apartment units, schools, and places of worship) are often disconnected.

- The concept of "community design" is new to many health organizations and associations. Community design is how communities/cities/urban areas are designed. It encompasses community planning, development, architecture, and transportation. $\mathrm{H}$ ealth organizations need to become more integrated with professionals in urban/ community planning, transportation, recreation, and design in order to participate in developing strategies that will make communities more activity-friendly.

- M any older adults do not know how to start a safe and proper home-based physical activity program.

- M any facilities that offer physical activity for older A mericans do not provide adequate training and monitoring for those who want to begin a physical activity program but lack skills.

- M any facilities that offer opportunities for physical activity for age 50 and older A mericans do not take into account that audience's preferences or needs for specific types of programs or services.

- M any older adults serve as caregivers for others, which can restrict their opportunities for regular physical activity.

- M any older adults are overweight and have chronic disease or disability, which can restrict their opportunities for regular physical activity.

- M any older adults may be isolated and lack transportation to community physical activity facilities and programs.

WO RK PLACE

- Good economic models illustrating the cost effectiveness to employers of increasing physical activity among older adults are needed.

- Employers may have concerns about liability. They may worry about the liability implications if an employee gets hurt or becomes ill while participating in an on-site physical activity program or event. 
- Little evidence exists about what programs are effective, and what measurable outcomes are most persuasive to management. For example, are employers most interested in improved performance and productivity, reduced health care costs, or reduced absenteeism?

- Workplaces have a high degree of variability, which may make workplace-based physical activity programs targeting older adults challenging to implement.

\section{MEDICAL SYSTEM S}

- Traditional medical education gives minimal attention to disease prevention. Training on physical activity is often a low priority, especially because most medical systems do not reimburse for physician counseling related to physical activity.

- A lack of data exists to recommend the dose and mode of physical activity for the frail elderly.

- Health care professionals often lack time to address physical activity. There is not an effective easy-to-use evidence-based protocol for health care systems (similar to the A sk, A dvise, A ssess readiness to change, Assist, and A rrange follow-up protocol used for tobacco cessation).

- H ealth care professionals do not have adequate, tested, and appropriate age-specific patient education materials for physical activity for older patients.

- $M$ any medical systems do not have in-house health promotion programs to assist patients in developing a physical activity program.

- M edical professionals do not have information about making referrals to community resources. They often lack knowledge about quality programs, materials, and resources.

\section{PUBLIC POLICY}

- Public policy organizations that could support increased physical activity initiatives are fragmented into areas such as public health, transportation, housing, parks and recreation, senior citizens issues, and health care reimbursement issues. No coalition or agency addresses these in a cross-cutting manner.

- N ot enough good economic models exist that illustrate the cost benefits of increasing physical activity among age 50 and older adults. Such models could be useful to policymakers in considering alternative investments in promoting physical activity among the age 50 and older population. 
MARKETING AND COMMUNICATIONS

- $M$ any of the messages and information about physical activity and exercise have been unclear, at times inconsistent, and confusing to older people, as well as to the general population, health professionals, and policymakers.

- There is minimal marketing research to define the perceptions, beliefs, and concerns of the age 50 and older population about physical activity and aging.

- Not enough effective messages to communicate information about physical activity have been developed and tested. These messages may need to take into account the continuum of health and functional status from healthy to frail adults.

\section{Addressing the barriers and setting a strategic direction}

The following approaches suggest ways to address barriers and strategies to increase physical activity among the aging population.

The strategies are divided into five categories: research, home/community, workplace, medical systems and public policy. Strategies that relate to more than one of these areas are listed as "cross cutting." M arketing and communications strategies are integrated throughout these recommendations.

In these recommendations "medical professionals" are defined to include physicians, nurses, nurse practitioners, and other allied health professionals.

These strategies should be considered by organizations that will implement this Blueprint. Specific programs or initiatives to support these strategies will be determined at an organizational level, and also through partnership and coalition work. Each organization will determine its priorities, based on its mission, existing strategic plan, and resources.

\section{CROSS-CUTTING STRATEGIES}

Cross-cutting strategies relate to multiple areas and involve coordination and integration among those working in research (epidemiology, social, behavioral, and marketing), home/ community, workplace, medical systems, public policy and marketing/communications.

1. Specify what interventions are most beneficial for segments of the 50 plus populations (active older adults, frail el derly, homebound, disabled, etc.).

2. Create a national clearinghouse to disseminate effective, tested public education, social marketing materials, and public policy information on physical activity and aging.

3. Evaluate current programs and devise systems to share and replicate effective programs. 
4. Seek opportunities for nonprofit associations and agencies to work collaboratively with the for-profit sector to develop joint public education programs. Involve groups including public health, health care organizations, community groups, faith institutions, schools, hospitals, and health clubs.

5. Establish and disseminate standards for fitness leaders who work with mid-life and older populations.

6. Conduct quantitative and qualitative research on effective social marketing strategies in communicating information about physical activity and older adults.

- Provide more information on how to segment and communicate effectively to the age 50 and older audiences.

- D evelop and test a mass-market communications campaign to increase awareness about the importance of physical activity in the health of age 50 and older Americans. Include messages related to what needs to happen to make opportunities for physical activity more accessible.

- Conduct market research to better understand how to leverage the social aspects and benefits of physical activity as a way to communicate and encourage people to be more active.

- Conduct market research on specific communications initiatives.

- Personalize messages to target audiences, using market research and audienceappropriate communication delivery systems.

- Identify and use "ambassadors" and celebrities to communicate to the 50 plus audiences.

7. Test the effectiveness and impact of emerging communications technologies including use of the Internet.

\section{RESEARCH STRATEGIES}

These strategies identify steps needed in research to include medical, social, behavioral, policy and marketing research. In many cases, integrating program development, implementation, and evaluation will be the most effective way to implement these strategies.

1. Conduct studies to characterize seniors who are currently active. These studies will include constructing a profile of this group (or groups) - who they are, what they do, what got them started, what sustains them, how they have overcome barriers. This profile could be useful in informing the work for individual and communitybased interventions, as well as broad public health interventions. 
2. Design and implement a comprehensive longitudinal study of activity-friendly communities to track their impact on reducing disease and disability, as well as improvements in people's quality of life.

3. Conduct behavioral research to understand better what motivates individuals to participate in community, home-based, and work site programs or self-directed activities.

4. Explore how to establish, maintain, and reinforce regular physical activity behaviors across multi-levels of intervention, e.g. personal, interpersonal, organizational, and environmental.

5. Identify barriers to walking for adults age 50 and older, determine why these barriers exist, and develop specific recommendations for how to overcome and avoid them.

6. Identify appropriate valid and reliable measures of physical activity and other health outcomes that can be used in future physical activity research targeting mid-life and older adults, which will increase the internal validity of studies and confidence in efforts to determine the effectiveness of home-based, community-based, and work site-based programs. These efforts will also increase the ability to compare findings from different studies and to better develop and disseminate best-practice guidelines and recommendations for creating effective programs.

7. Conduct research and disseminate findings to inform health program developers, social marketers and health care professionals to understand what interventions or factors influence the physical activity of age 50 and older adults. These factors or determinants might include significant life events such as the death of a spouse or a move to a retirement community, etc.

8. Conduct research to understand better the elements of effective work site programs that focus on mid-life and older workers. Disseminate findings and best-practice guidelines.

9. Evaluate the cost benefit of increased physical activity within assisted living facilities.

10. Conduct research related to HCFA/M edicare guidelines for physical activity and the older populations.

HOME/COMMUNITY STRATEGIES

Home and community strategies take into account the nature of how people live and carry out the normal tasks of daily life.

1. Highlight examples of activity-friendly communities and home/community-based programs, including a system to share best practices. Identify what programs exist, what works, and what evaluation mechanisms are in place. 
2. Develop and test appropriate programs for living arrangements, such as assisted living communities or naturally occurring retirement communities.

3. Educate people about physical activity and have physical activity professionals such as trainers and fitness instructors work with older people to teach and reinforce skills.

4. Encourage more health, physical education, recreation, and dance professionals to become certified/trained in working with older adults.

5. Identify professionals in the community who can serve as resources for information and assistance. Work as much as possible with existing community groups such as the Y M / Y WCA, community centers, senior centers, health and sports clubs, schools, places of worship, and hospital wellness programs, etc.

6. Provide funding and implement physical activity programs for older adults through existing appropriate community facilities such as Y M /Y WCA, community centers, senior centers, places of worship, etc.

7. Identify and assess existing group physical activity programs that can be translated into self-directed programs. Share information related to best practices.

8. Provide community organizations with a template for good physical activity programs: O utline the elements of a good program including facilitator qualifications, monitoring, evaluation, and sustainability issues. Identify "best practice" physical activity programs for adults age 50 and older that can be replicated and generalized.

9. Design and implement a health-impact assessment that is similar to an environmental impact assessment for communities.

10. Establish partnerships among health, aging, urban/community planning, transportation, environmental groups, recreation, social service, and the private sector. Encourage these groups to work together to define, create, promote, and sustain communities that support lifelong physical activity.

\section{WORKPLACE STRATEGIES}

These strategies recognize that people generally work in or near the community in which they live, and work sites can often operate as a community resource or center.

1. Seek employee input in the planning and development of programs targeted to the age 50 and older worker.

2. Create a workplace environment where time for physical activity is incorporated into daily activities. 


\section{"N o one is too old to enjoy the benefits of regular}

physical activity. Of special interest to older adults is evidence that musclestrengthening exercises can reduce the risk of falling and fracturing bones and can improve the ability to live independently."

PHYSICAL ACTIVITY AND HEALTH A REPORT OF THE SURGEON GENERAL 
3. D esign a system that provides employers with tax incentives based on physical activity programs/opportunities they afford their employees.

4. Provide financial incentives to employers that incorporate physical activity enhancements in their corporate setting land-use plans.

5. Provide health insurance cost reductions to employers that offer physical activity programs to employees.

6. D evelop, implement, and evaluate model work site physical activity programs, targeted to employees age 50 and older.

7. Provide tools and templates to enable employers to communicate information about the importance of physical activity.

8. Identify and disseminate information about successful work site physical activity programs designed for employees age 50 and older.

9. Communicate to business leaders the benefits of physical activity for older workers, especially as they pertain to desired outcomes of management (e.g. cost-savings, employee absenteeism, etc.).

\section{MEDICAL SYSTEM S STRATEGIES}

$M$ edical systems are broadly defined to include health care delivery centers, e.g. clinicians' offices, clinics, medical centers, hospitals, and health care reimbursement organizations. Professional education and continuing education are covered in these strategies.

1. Assist health care systems in establishing methods to gather information on current practices related to physical activity assessment, counseling, and follow-up with mid-life and older patients.

2. Incorporate "best practices" on physical activity into education programs for all health care professionals.

3. Develop an evidence-based approach and practice guidelines to deliver physical activity programs and information through health care settings. Provide professionals with education on how to implement such initiatives. Implementation might include the approach of A sk, Advise, A ssess, A ssist and A djust.

4. Increase health care professional training on physical activity in older populations. Such training should be available through medical and health care professional schools and through continuing education programs for physicians, sports medicine professionals, occupational and physical therapists, nurses, and health educators. 
5. Encourage medical students and medical professionals (physicians, nurses and other allied health professionals) to be more physically active in order to serve as role models for patients.

6. Enlist experts working in health care systems to help identify effective components of physical activity programs for people age 50 and older.

7. Identify community resources, (i.e. Y M /Y WCAs, certified trainers, fitness clubs, etc.) which are quality sources for information related to physical activity and the age 50 and older adult and provide this information to consumers via medical settings.

8. Increase coordination and develop partnerships between medical professionals and the community to facilitate referrals and information sharing. Provide health and medical professionals with information and resources about physical activity opportunities for the older population so that they can make referrals and recommendations as appropriate.

9. Assist patients in identifying physical activity options that match their interests, lifestyles, and functional abilities; and identify opportunities for them to pursue these.

10. Establish and share with health care professionals minimum standards for physical activity among older adults in terms of endurance, strength, flexibility, and balance.

11. D evelop standards to accommodate physical activity programs in nursing care/ assisted care facilities that focus on reacquisition of mobility after illness or injury as well as maintenance of regular physical activity.

12. Develop materials, guidelines, and toolkits to enable health care providers to more effectively communicate with patients the benefits of physical activity.

13. Disseminate information about physical activity in the age 50 and older persons to health professionals via professional journals, professional societies, meetings, and related media.

14. Establish and evaluate health and wellness programs in health care settings that rely on trained allied health professionals rather than physicians to provide patients with physical activity assessments and counseling.

15. Demonstrate the cost effectiveness of these strategies to managed care organizations and health insurance companies. 
POLICY / A DVOCACY STRATEGIES

Public policy and advocacy strategies can be carried out at the local, state and national level. Effective policy/advocacy initiatives should include coordination and collaboration among organizations and associations that share priorities and objectives.

1. Develop committed coalitions/partnerships to build leadership and capacity, leverage resources, and provide an ongoing forum for organizations to share information and ideas that can be implemented in a variety of settings.

2. Engage constituents in advocacy activities.

- O rganize older adults to become more directly involved in making their neighborhoods and communities more walkable.

- Involve health care professionals, clergy, and business leaders in advocating for activity-friendly communities.

- Involve professional organizations/associations in advocating for activity-friendly communities.

3. Channel tools and funds to communities so that they can implement actions designed to increase physical activity among mid-life and older adults.

- Provide incentives to states and communities that achieve measurable increases in the physical activity levels of the 50 and older population.

- Provide funding to low-income populations and publicly funded community organizations and programs to make physical activity opportunities more readily available and accessible for age 50 and older adults.

- Identify barriers to increasing local and state funding to create activity-friendly communities and to assure easy access to physical activity programs for all persons age 50 and older.

- Provide community organizations with help in developing long-term, sustainable funding for physical activity programs, training, and resources for the age 50 and older population.

4. Educate policymakers about the importance of physical activity for the age 50 and older population, emphasizing the social, economic, and health benefits. Include information that provides examples of effective policy in this arena. 
5. Conduct a policy analysis of health plans that offer benefits related to physical activity for mid-life and older adults.

- D evelop, implement, evaluate, and disseminate a model policy for quality of care related to physical activity for older adults.

- D esign and test a program to provide people with reductions in health insurance costs based on physical activity levels.

6. Advocate for funding for program and policy analysis research on physical activity and the age 50 and older population. Advocate for increases in funding to disseminate research findings and translate practice guidelines into practice.

7. Support the development of safe activity-friendly communities.

8. Provide information on the cost effectiveness of increasing regular physical activity among the age 50 and older population to help support public policy, program, and reimbursement efforts.

9. D evelop a national scorecard to outline what makes a community activity-friendly for older adults, and publicize rankings. 


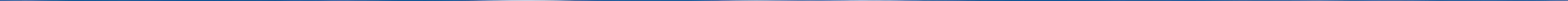




\section{Moving toward and beyond 2010: Turning strategies into action}

The following action steps can help mobilize use of this document:

1. O rganizations should identify which of the strategies they are already addressing or will address, and collaborate with other groups that share an interest in that (those) strategy(ies.) 0 rganizations should make efforts to work with existing coalitions and coordinate with other groups and organizations. Participating organizations should also identify and involve other organizations that are not working on this issue, but that can play a major supportive role.

2. O rganizations, associations, and agencies working collaboratively should focus on activities that they can reasonably expect to accomplish.

3. O rganizations need to undertake detailed tactical planning to delineate the specific actions that are needed to achieve the strategies.

4. O rganizations will need to allocate money and people to help support coalition and collaborative efforts.

5. H ealth organizations and government agencies must encourage the exchange and dissemination of best practices. These groups must establish systems to enable this.

6. Evaluation should be a key tool in all implementation steps. In some cases evaluation can be objective, based on set measurable objectives. In other cases evaluation will be process or formative.

This Blueprint is designed to support an increase in physical activity among age 50 and older adults, and ultimately to improve the health and well-being of all A mericans. The key to success lies in developing and channeling resources and working collaboratively to move the evidence about the benefits of physical activity into national action. 


\section{Acknowledgments}

The following individuals and organizations have provided input into the development of this document

The $\mathrm{N}$ ational Blueprint: Increasing Physical A ctivity Among A dults Age 50 and 0 Ider became a reality in large part due to the dedicated work of the Blueprint Steering Committee. Special acknowledgement and thanks go to the following individuals and organizations that made up this committee:

\begin{tabular}{|c|c|}
\hline A A R P & David Buchner, M D, PhD \\
\hline SARAh ARM StRONG & Chief, Physical Activity and $\mathrm{H}$ ealth Branch \\
\hline Director of Organizational Relations & $\begin{array}{l}\text { Division of N utrition and Physical A ctivity } \\
\mathrm{N} \text { ational Center for Chronic Disease }\end{array}$ \\
\hline Katrin Ka Smith SLOan, M A & Prevention and $\mathrm{H}$ ealth Promotion \\
\hline $\begin{array}{l}\text { Director, M embership Education } \\
\text { and Information }\end{array}$ & $\begin{array}{l}\text { The N ational Institute on A ging } \\
\text { M ARCIA ORY, PHD, M PH }\end{array}$ \\
\hline $\begin{array}{l}\text { M ARY CON N OLLY T URNER } \\
\text { Program Consultant, H ealth }\end{array}$ & Chief, Social Science Research on A ging \\
\hline $\begin{array}{l}\text { A merican College of Sports M edicine } \\
\text { WoJTEK CHODZKO-ZAJKO, PHD } \\
\text { Department of Kinesiology }\end{array}$ & $\begin{array}{l}\text { Director, O ffice of Communication and } \\
\text { Public Liaison }\end{array}$ \\
\hline University of Illinois at Urbana & $\begin{array}{l}\text { The Robert Wood Johnson Foundation } \\
\text { H INDA GREen BERG, PHD }\end{array}$ \\
\hline $\begin{array}{l}\text { American Geriatrics Society } \\
\text { LIN DA H IDDEM EN BARONDESS }\end{array}$ & Director, Information Center \\
\hline Executive Director & $\begin{array}{l}\text { M ARLA H OLLANDER, M PH } \\
\text { Program Associate }\end{array}$ \\
\hline MICHAEL O'GRADY, MD & \\
\hline Chief of Rehabilitation M edicine & Robin Mockenhaupt, PhD \\
\hline Emory H ealth Care & Senior Program O fficer \\
\hline $\begin{array}{l}\text { The Centers for D isease Control } \\
\text { and Prevention } \\
\text { DAVID BRown, PHD }\end{array}$ & $\begin{array}{l}\text { C. TRACY ORLEANS, PHD } \\
\text { Senior Scientist and Senior Program O fficer }\end{array}$ \\
\hline $\begin{array}{l}\text { Division of } \mathrm{N} \text { utrition and Physical A ctivity } \\
\mathrm{N} \text { ational } \mathrm{C} \text { enter for Chronic Disease } \\
\text { Prevention and } \mathrm{H} \text { ealth Promotion }\end{array}$ & $\begin{array}{l}\text { BRIGID M CHUGH SANNER } \\
\text { Consultant }\end{array}$ \\
\hline
\end{tabular}


Special thanks go to these scientists who contributed to the Blueprint by preparing

and/or presenting background papers that helped inform the development of this plan.

Audie Atienza, PhD

Stanford University School of M edicine

Elizabeth Eakin, PhD

Q ueensland University of Technology

School of Public Health and Human

M ovement Studies, and AM C Cancer

Research Center
LAURA LINNAN, SCD

University of N orth Carolina School

of Public Health

Anita Stewart, PhD

University of California at San Francisco

And to these individuals who made presentations at the Blueprint Conference: Increasing Physical Activity A mong Adults Age 50 and Older.

Walter BortZ, M D

Palo Alto M edical Foundation

Mark Fenton

Walking M agazine

Michael Goldstein, M D

Bayer Institute for $\mathrm{H}$ ealth $\mathrm{C}$ are

Communications
MICHAEL M CGINNIS, M D

The Robert Wood J ohnson Foundation

William N OVELli, M A

AARP

The following individuals and organizations participated in the Blueprint Conference and/or provided review and input into the document.

\section{AARP}

SARAh ARm Strong

ELINOR GINZLER

MARGARET D. HAWKINS, MS

William N OVELLI, M A

Katrinka Smith Sloan, M A

Mary CONNOLLY TURner

Alliance of Community H ealth Plans

JonAthan GELFAnd
A merica Walks

SAlLY Flocks

A merican A cademy of Family Physicians JACQUELYN AdM IRE-BorgelT

A merican A cademy of $\mathrm{N}$ urse Practitioners Jan TOWERs, PhD 
A merican Alliance for $\mathrm{H}$ ealth, Physical Education, Recreation and D ance and the A merican Association for Active Lifestyles and Fitness

Jan Seaman, PhD

A merican Cancer Society

Colleen Doyle

A merican College of Sports M edicine

Wojtek Chodzko-Zajko, PhD

Loretta DiPietro, PhD

JAMES WHITEHEAD

A merican Geriatrics Society

LINDA HIDDEMEN BARONDESS

MICHAEL O'GRADY, MD

A merican H eart Association

Katherine Krauss

A merican $O$ ccupational Therapy Association

Brena Manoly, PhD, OT

A merican Red Cross

NANCY M CKELVEY

A merican Society on Aging

Gloria Cavanaugh

Arthritis Foundation

M ichele Boutaugh, M PH

Assisted Living Foundation of America

Judy CONOVER

Association for Work Site H ealth Promotion

David Chen oweth, PhD

Barrington \& Chappell

SuzAnne Mercure
Bayer Institute for H ealth Care

Communications

M ichael Goldstein, M D

Center for Livable Communities/A merican

Institute of A rchitects

Stephanie Bothwell

The Centers for D isease Control

and Prevention

David Brown, PhD

David Buchner, M D, PhD

William Dietz, M D, PHD

Elizabeth H. HOWZe, PhD

Suzanne M. Sm ith, PhD

Judy Stevens, PhD

Fifty Plus Fitness A ssociation

RAY S. Stewart

Gerontological Society of America

M OHAMM ED ReYAZUDdIN

H ealth Canada, Fitness A ctive Living Unit

BRUCE TAYlor

International $\mathrm{H}$ ealth, Racquet and

Sportsclub A ssociation

KeVIn BuCKLeY

$\mathrm{N}$ ational Association for $\mathrm{H}$ ealth and Fitness

Cindy Porteous

$\mathrm{N}$ ational Association of A rea Agencies on A ging

ShaWn MCDERM OTT

$\mathrm{N}$ ational Center for Bicycling and Walking

WILLIAM WILKERSON

$\mathrm{N}$ ational Center on Physical A ctivity

and Disability

JAMES H. RIM MER, PHD 
$\mathrm{N}$ ational Council on the $\mathrm{A}$ ging

LYNN BEATTIE

Nancy Whitelaw, PhD

N ational H ighway Traffic Safety

Administration

LAURIE FLaherTy, RN, M S

$\mathrm{N}$ ational $\mathrm{H}$ ispanic Council on A ging

M ARTA SOTOMAYOR, PhD

The N ational Institute on Aging

M ARCIA ORY, PHD, M PH

JANE SHURE

N ational Recreation and Parks A ssociation

Kathy Spangler

N ational Senior Games A ssociation

LISA C. ClOUgh

Palo Alto M edical Foundation

Walter Bortz, M D

Partnership for Prevention

M OLLY FRENCH

President's Council on Physical Fitness

and Sports

Christine Spain

Research A merica

LORI COOPER

The Robert Wood J ohnson Foundation

Hinda Green berG, PhD

MaRLA H OLLANDER, M PH

MICHAEL MCGINNIS, M D

ROBIN M OCKENHAUPT, PHD

C. Tracy Orleans, PhD

BRIgID M CHUGH SANNER
Sporting G oods M anufacturers Association

M ARIA Steffan

Stanford University School of M edicine

Audie Atienza, PhD

ABBY KING, PHD

University of California at San Francisco

Anita Stewart, PhD

University of N orth Carolina School of

Public Health

LAURA LINNAN, SCD

US D epartment of $\mathrm{H}$ ealth and $\mathrm{H}$ uman

Services $O$ ffice on Women's $H$ ealth

and the $\mathrm{N}$ ational A eronautics and Space

Administration

SARALYN MARK, MD

US D epartment of Veterans Affairs

Judith Salerno, M D

Visiting N urse Association of America

Pamela Sawyer, RN, M HA

Walking M agazine

M ARK FENTON

YWCA

M ARGARET TYNDALL 
F O O T N O TES

${ }^{1}$ Successful A ging, Rowe, J.W. and Kahn, R.L., Pantheon Books, 1998

${ }^{2}$ Older A mericans 2000: Key Indicators of Well-Being, $\mathrm{N}$ ational Institute on Aging

${ }^{3}$ Older A mericans 2000: Key Indicators of Well-Being, $\mathrm{N}$ ational Institute on A ging

${ }^{4}$ O Ider A mericans 2000: Key Indicators of Well-Being, $\mathrm{N}$ ational Institute on Aging

${ }^{5}$ Older A mericans 2000: Key Indicators of Well-Being, $\mathrm{N}$ ational Institute on Aging

${ }^{6}$ Promoting Physical A ctivity, US D epartment of H ealth and H uman Services, 1999

${ }^{7}$ Exercise: A guide from the $\mathrm{N}$ ational Institute on A ging, $\mathrm{N} \mathrm{IH} \mathrm{99-42588}$

${ }^{8}$ Exercise: $\mathrm{A}$ guide from the $\mathrm{N}$ ational Institute on A ging, $\mathrm{N} \mathrm{IH} \mathrm{99-4258}$

${ }^{9}$ Exercise: A guide from the $\mathrm{N}$ ational Institute on A ging, $\mathrm{N} \mathrm{IH} 99-4258$

${ }^{10}$ Exercise: A guide from the $\mathrm{N}$ ational Institute on A ging, $\mathrm{N} \mathrm{IH} \mathrm{99-4258}$

${ }^{11}$ O Ider A mericans 2000: Key Indicators of Well-Being, $\mathrm{N}$ ational Institute on Aging

${ }^{12} \mathrm{O}$ Ider A mericans 2000: Key Indicators of Well-Being, $\mathrm{N}$ ational Institute on Aging

${ }^{13}$ A merican Geriatrics Society, Foundation for H ealth in A ging Fact Sheet

${ }^{14} \mathrm{H}$ ealth and $\mathrm{H}$ ealth Care 2010, The Institute for the Future, Jossey-Bass Publishers, 2000.

${ }^{15} \mathrm{O}$ Ider A mericans 2000: Key Indicators of Well-Being, $\mathrm{N}$ ational Institute on A ging

${ }^{16}$ O Ider A mericans 2000: Key Indicators of Well-Being, $\mathrm{N}$ ational Institute on A ging

${ }^{17}$ O Ider A mericans 2000: Key Indicators of Well-Being, $\mathrm{N}$ ational Institute on A ging

${ }^{18}$ Physical A ctivity Interventions Targeting O Ider A dults, A m J Prev. M ed, 1998:15(4), pp. 316-333

${ }^{19} \mathrm{O}$ Ider A mericans 2000: Key Indicators of Well-Being, $\mathrm{N}$ ational Institute on A ging

${ }^{20} \mathrm{~J}$ ohns H opkins M edical Institutions, N ews release, September 8, 2000,

${ }^{21} \mathrm{~N}$ ational $\mathrm{O}$ steoporosis Foundation

${ }^{22}$ Successful A ging, Rowe, J.W. and Kahn, R.L., Pantheon Books, 1998

${ }^{23} \mathrm{~N} \mathrm{IH}$ C onsensus Statement, N ational Institutes of H ealth 1995

${ }^{24}$ Exercise and O Ider Patients: Guidelines for the Clinician, JAGS, M arch 2000, Vol. 48, N o. 3, pp. 318-324

${ }^{25}$ Physical Activity and $\mathrm{H}$ ealth: A Report of the Surgeon General

${ }^{26}$ Therapeutic and Physical Fitness Exercise Prescription for O Ider A dults with Joint

Disease: An Evidence-Based A pproach. Geriatric R heumatology, August 2000, Vol 26, N o. 3, pp. 617-646.

${ }^{27}$ Centers for Disease Control and Prevention. Physical A ctivity Trends - U nited States 1990-98. M M WR 50(9): 166-169, 2001

${ }^{28}$ Physical Activity and $\mathrm{H}$ ealth: A Report of the Surgeon General

${ }^{29}$ White Paper on Physical A ctivity in O Ider A dults. Prepared for The Robert Wood Johnson Foundation. Rejeski, W.J. and Brawley, L.R., M arch 15, 2000.

${ }^{30}$ Prevalence and correlates of physician recommendations to exercise among older adults. Damush, TM , J G erontol M ed Sci 1999, 54A (8):M 4423-27

${ }^{31}$ USD H HS, H ealthy People 2010. 2nd Edition. 2 Volumes. Washington, D.C. US Government Printing $O$ ffice. 2000

${ }^{32}$ Preparation for A ging, M cKinlay, J.B. in Heikkinen, E., Ruoppila, I, and Krusinen, J. (Eds). London: Plenum Press. 1995. 